\title{
Decentralized Control Strategy for an AC Co-Phase Traction Microgrid
}

\author{
Lan Ma ${ }^{1}$, Yuhua Du ${ }^{2, * \mathbb{D}}$, Leilei Zhu ${ }^{1}$, Fan Yang ${ }^{1}$, Shibiao Xiang ${ }^{1}$ and Zeliang Shu ${ }^{1}$ \\ 1 School of Electrical Engineering, Southwest Jiaotong University, Chengdu 611756, China; \\ mlan@swjtu.edu.cn (L.M.); zhuleilei@my.swjtu.edu.cn (L.Z.); jalorfy@my.swjtu.edu.cn (F.Y.); \\ xsb@swjtu.edu.cn (S.X.); shuzeliang@swjtu.edu.cn (Z.S.) \\ 2 College of Engineering, Temple University, Philadelphia, PA 19122, USA \\ * Correspondence: yuhua.du@temple.edu
}

\begin{abstract}
High speed and heavy loads have become more prevalent in the traction power supply system recently. To ensure system operating stability, better power quality, and sufficient power capacity, improvements are needed over the conventional traction system. Inspired by the concept of a microgrid (MG), an AC co-phase traction MG system was proposed. Substations were connected to the traction grid as distributed generators operate in islanded mode. Droop control was adopted as the primary control to stabilize the system's operating frequency and voltage. Considering the operating features of the substation and locomotive load, a de-centralized secondary control strategy was proposed for AC co-phase traction MG system operation with enhanced resiliency. The proposed control strategy could increase system stability and prevent circulation currents between substations. Moreover, the proposed de-centralized coordination between substations does not rely on communication, which promotes the system's "plug-and-play" functionality. Stability analysis was undertaken and the proposed controller was proved to be exponentially stable. The dynamic response of the proposed controller was validated using comprehensive case studies in MATLAB/Simulink.
\end{abstract}

Keywords: circulation current; co-phased traction system; secondary control; microgrid

Citation: Ma, L.; Du, Y.; Zhu, L.; Yang, F.; Xiang, S.; Shu, Z. Decentralized Control Strategy for an AC Co-Phase Traction Microgrid. Energies 2021, 14, 7. https://dx.doi.org/10.3390/en1 4010007

Received: 6 November 2020 Accepted: 14 December 2020 Published: 22 December 2020

Publisher's Note: MDPI stays neutral with regard to jurisdictional claims in published maps and institutional affiliations.

Copyright: (C) 2020 by the authors. Licensee MDPI, Basel, Switzerland. This article is an open access article distributed under the terms and conditions of the Creative Commons Attribution (CC BY) license (https: / / creativecommons.org/ licenses/by/4.0/).

\section{Introduction}

With the development of high-speed rail, the requirements for traction power quality and capacity have increased [1]. A conventional railway traction power system suffers from critical power quality problems, such as voltage unbalance, poor power factor, and harmonic distortion. To compensate for the reactive power and harmonics of the catenary, a co-phase traction power supply system was proposed based on the design of an active power compensator [2,3]. A benefit of the co-phase system is that half of the neutral sections can be canceled. To link all the catenaries of the substations without any neutral sections, an advanced co-phase system was proposed in [4]. Instead of a traction transformer, a three-phase to single-phase converter was adopted by the substation [5]. Therefore, the traction voltage can be controlled and there's only one catenary in the system. However, the system could be destabilized with varying line impedances or loading conditions.

The substations could be controlled as distributed generators (DGs), and the advanced co-phase traction power grid could be treated as a special type of microgrid (MG). Different from a conventional MG [6,7], there are several unique characteristics of a traction MG. First, the locomotive load moves on the traction grid, which means that the system impedance distribution changes regularly. Second, due to the unique features of the traction power infrastructure, the distance between two substations is fixed to dozens of kilometers, which results in a non-ignorable line impedance effect. Third, unlike the DGs with various capacities, converter-based substations with an identical power capacity are connected to the traction grid. Automatic power-sharing in response to the line impedance variation should be realized [8], which is different from the proportional power-sharing in a conventional 
MG $[9,10]$. Lastly, since the traction power system is an autonomous AC system, the AC traction MG operates constantly under islanded operation mode [11,12].

Coordinated operation between multiple DGs in the context of autonomous MG operation has been frequently discussed in the literature. Conventional islanded MGs contain multiple inverter-based DGs that are installed in parallel [13]. Differing in their control objectives, there are three typical control modes, namely, P/Q control, V/F control, and droop control [14]. Under P/Q control, a DG inverter operates as a current source whose power output is as commanded. In contrast, a fixed voltage and frequency reference is adopted by the inverter in $\mathrm{V} / \mathrm{F}$ control. Due to the differences in inverter impedance and capacity, an overcurrent problem would be frequently generated when multiple $\mathrm{V} / \mathrm{F}$-controlled inverters operate in parallel [15]. Moreover, a V/F-controlled DG normally operates as the only slack node in an islanded MG, which requires its installed power capacity to be sufficiently large. To automatically stabilize the system frequency and voltage while achieving DG power-sharing, droop control is proposed $[16,17]$. However, due to system line impedance variation, mismatched DG reactive power-sharing is inevitable in conventional droop control [18]. To ensure system operation synchronization, voltage regulation, power balance, and load sharing, many advanced control strategies are carried out. Improved droop control [19,20], virtual impedance-based control [21,22], and improved hierarchical control strategies [23] are often adopted to eliminate the frequency and voltage deviations caused by droop control and achieve accurate power-sharing [24,25].

Similar challenges to voltage regulation and power-sharing exist in an advanced co-phase traction system. Inspired by the concept of an MG, an AC co-phase traction MG was proposed in this study.

- Considering the characteristics of a traction system, a decentralized control strategy was proposed to enhance the traction MG operating performance. In the proposed strategy, no communication between substations was introduced, which makes it easier for the substation to realize plug-and-play functionality.

- Due to the benefit of automatic power-sharing between substations, the capacity of the high-speed railway could easily be expanded through the connection of more substations without modification, which differs from the ones in a conventional traction grid.

- As the primary control is implemented, the traction grid operating frequency and voltage can be stabilized via autonomous regulation through multiple substations coordinating together. In addition, the phase and voltage magnitude error is eliminated in the secondary control. Despite the effect of the long-distance line impedance, the traction grid voltage is maintained in an acceptable range along the catenary line. Moreover, the circulation current is eliminated due to the elimination of the substation voltage difference.

- Without neutral sections, there is only one catenary in a traction MG, which makes it more flexible for distributed renewable resources to integrate with the traction grid in the future.

The rest of this paper is constructed as follows. The proposed AC co-phase traction MG system is introduced in Section 2. In Section 3, the line-impedance-based powersharing and circulation current are analyzed and the proposed control strategy is presented. The small-signal stability of the system is analyzed in Section 4 . Simulations results based on three substations are derived in Section 5 to validate the effectiveness of the proposed strategy for the AC co-phase traction MG system.

\section{AC Co-Phase Traction Microgrid}

In an advanced co-phase system, only one catenary line is utilized, which does not require a neutral section. All substations are connected to the single-phase AC traction grid [4]. Inspired by the concept of an MG, an AC co-phase traction MG is proposed in this section. The system topology is presented schematically in Figure 1. 


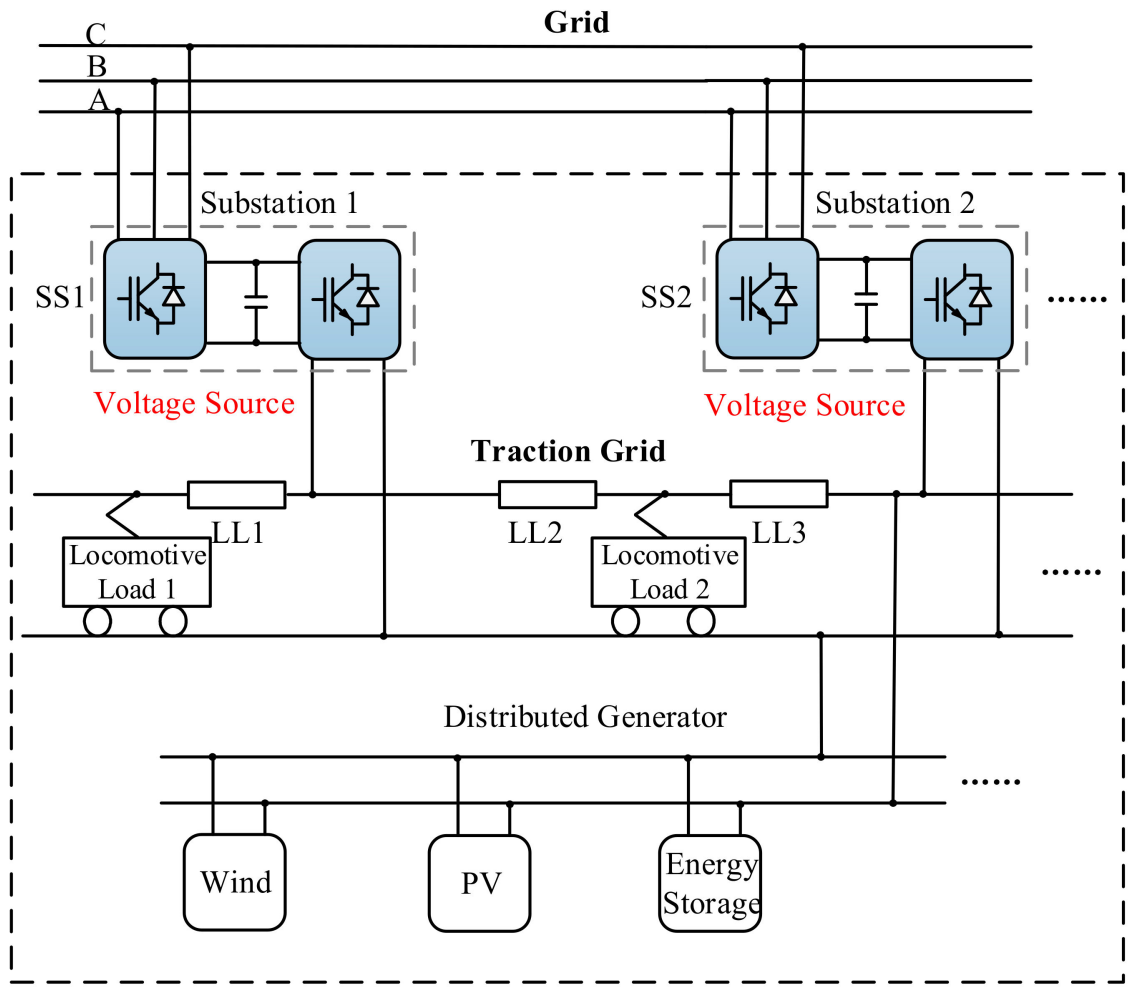

AC Co-phase Traction Micro-Grid

Figure 1. AC co-phase traction microgrid (PV: photovoltaics).

As shown in Figure 1, substations are utilized to stabilize the traction grid and energize the locomotive loads. The traction MG and the main grid are interconnected by substations through AC/AC converters (SS1 and SS2). Compared to a conventional transformer, a converter-based substation operates as a controllable voltage source with better controllability. Due to the characteristics of an AC co-phase traction MG, the substation converter always operates under islanded mode. The distance between the substations is normally at the kilometer $(\mathrm{km})$ level and the effect from the line impedance (LL1, LL2, and LL3) is non-negligible. Additionally, the capacity of each substation is identical, which is different from the case in a typical MG where the generation capacities would vary.

Only a locomotive load is presented in the traction MG. As the trains move, the loads are not connected at fixed points. Line impendence between the source and load is constantly changing, and thus, power-sharing between substations is difficult to achieve using the conventional droop controller. Based on a line impedance change, an automatic power-sharing strategy can be adopted. The locomotive load will automatically be energized by the nearest substation. Such a method is not only easy to apply but also maintains the operation voltage of the loads within an acceptable range all the time.

Additionally, DGs can also be directly connected to the traction grid. The power generated by the DGs can be utilized to support loads or flow into the grid through the substation. Without any neutral section, it is also more flexible for DGs to connect with the traction gird. As a result, the proposed traction MG will help with renewable penetration along the railway.

\section{Proposed Traction MG}

In an islanded MG, at least one voltage source that acts as a slack bus needs to be present. However, in a traction grid, all the substations are distributed on one long feeder. If only one slack bus is presented, due to the line impedance effect, the system will be destabilized by the substations that are far away [5]. As the voltage difference between the substations increases, there will also be more power losses caused by the circulation current. 
To achieve a robust system, all the substations are operated as a voltage source, which supports the voltage of the traction MG. A decentralized control strategy is proposed for the substations on the traction grid, as shown in Figure 2. In the traction system, the catenary line impedance changes the locomotive location. For an effective load power allocation, an automatic power-sharing function can be achieved under this control strategy. Furthermore, a two-layer-based control strategy is designed for the system stability enhancement and the output voltage synchronization. In the following section, the circulation current between the substations is first analyzed; then, primary control and secondary control strategies are introduced for the substation operation in the traction MG.

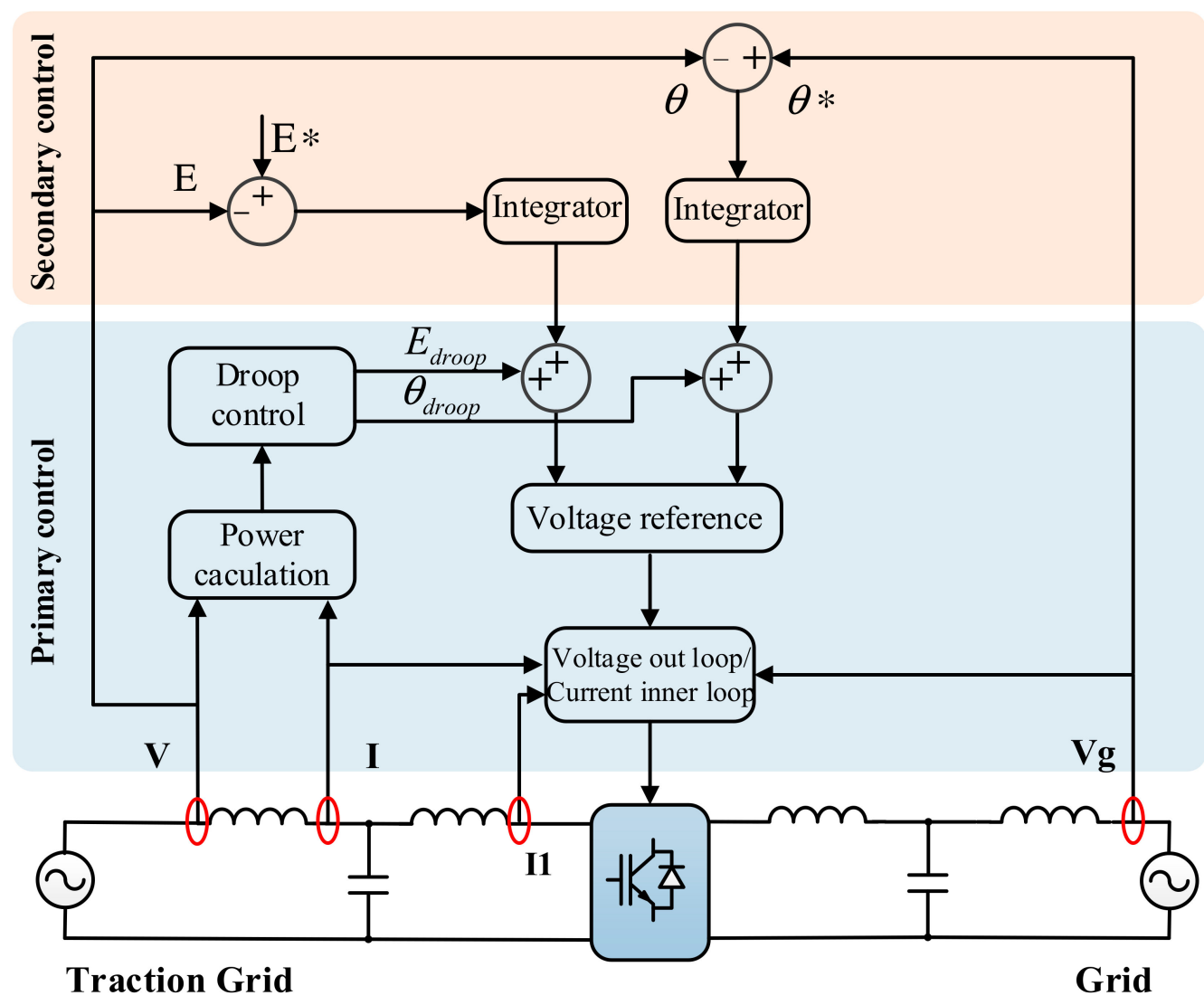

Figure 2. The proposed decentralized control strategy for the substation in the traction microgrid.

\subsection{Line-Impedance-Based Power-Sharing and Circulation Current between the Substations}

In a conventional traction power grid, only one substation provides power in each interval. There will be a significant voltage drop at the end of each interval due to the long-line impedance. Without a neutral section, the substations in a traction MG could operate in coordination and the voltage drop could be effectively reduced. Figure 3 presents an equivalent circuit of a traction MG with two substations.

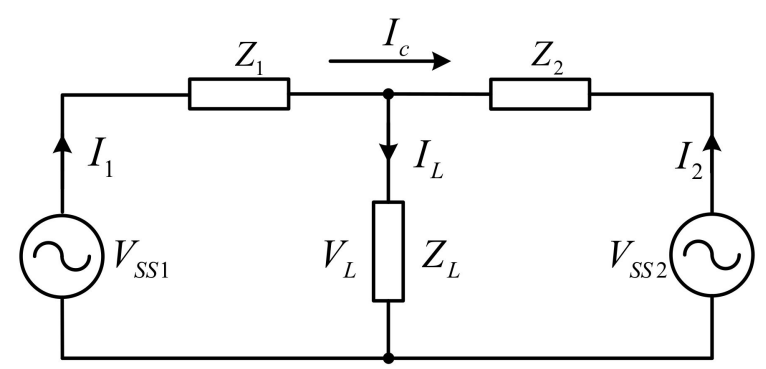

Figure 3. Equivalent circuit of two substations. 
In Figure $3, Z_{1}$ and $Z_{2}$ represent the line impedances between two substations $V_{S S 1}$ and $V_{S S 2} ; Z_{L}$ is the reactance of the locomotive load; $I_{1}, I_{2}$, and $I_{L}$ are the currents of $V_{S S 1}$, $V_{S S 2}$, and the load. When the output voltages of $V_{S S 1}$ and $V_{S S 2}$ are equal, the system current flows are described as follows:

$$
\begin{aligned}
& I_{1}=\frac{Z_{2}}{Z_{1}+Z_{2}} I_{L} \\
& I_{2}=\frac{Z_{1}}{Z_{1}+Z_{2}} I_{L} .
\end{aligned}
$$

The values of $Z_{1}$ and $Z_{2}$ depend on the location of the locomotive load. It can be seen that when the load moves toward the substation $V_{S S 1}$, the line impedance $Z_{1}$ gets smaller. Referring to Equations (1) and (2), in this case, the current $I_{1}$ increases while the current $I_{2}$ decreases. This indicates the fact that the load will get more energy from the nearest substation. In conclusion, automatic line-impedance-based power-sharing is achieved in this traction power system. Compared to a conventional traction grid, the voltage drop on the line impedance would be maintained in an acceptable range, which will be discussed in detail in Section 5.

A voltage difference between two substations will result in circulation currents. Such currents will flow through the line impedance between two sources and eventually be fed back to the grid through a converter. This would not only cause extra energy loss due to the line impedance and the power electronic devices but will also have a negative effect on the converter power stress and lifetime. The circulation current is defined as:

$$
I_{c}=\frac{V_{1}-V_{2}}{Z_{1}+Z_{2}},
$$

such that Equations (1) and (2) can be rewritten as:

$$
\begin{aligned}
& I_{1}=\frac{Z_{2}}{Z_{1}+Z_{2}} I_{L}+I_{\mathcal{c}} \\
& I_{2}=\frac{Z_{1}}{Z_{1}+Z_{2}} I_{L}-I_{\mathcal{c}} .
\end{aligned}
$$

If the output voltages of substations $V_{1}$ and $V_{2}$ are regulated as rated, there would be no voltage difference (i.e., $V_{1}=V_{2}=E^{*}$ and $V_{1}-V_{2}=0$ ) and the circulation current can be eliminated.

\subsection{Primary Control}

In this work, a three-phase converter was adopted to stabilize the DC link voltage, while a single-phase converter was applied to maintain the traction grid voltage and support the locomotive load consumption. Three control loops were introduced under primary control, namely, droop control, a voltage out loop, and a current inner loop. DC bias current control was adopted for the inner current loop [26]. The D/Q voltage reference was generated by the voltage out loop. In [5], the voltage loop reference came from the sampling voltage/phase values from the connection point of each substation in the traction grid. When the initial state is changed, such as in the load condition, the system will collapse. Moreover, there is only one voltage source in the advanced co-phase traction grid. The long-distance line impedance between the substations and voltage source will cause a considerable voltage drop and become a threat to the stability of the system. Droop control is widely implemented in islanded MG to stabilize the voltage. In a high voltage traction power system where the line impedances are inductive $(X>>R)$, droop control is suitable for this system. In order to autonomously stabilize the traction grid operating frequency and voltage using multiple substations in coordination, droop control is implemented at each substation. Based on the calculation of the power at the output 
connection point, the voltage amplitude and phase reference are generated according to the droop function.

\subsection{Secondary Control}

Due to the inherent characteristics of droop control, steady-state deviations will be introduced to both the system operating frequency and voltage magnitude [27]. In this study, secondary control was implemented for further regulation. As shown in Figure 2, $E^{*}$ and $\theta^{*}$ represent the rated voltage magnitude and phase, while $E$ and $\theta$ represent the substation output voltage magnitude and phase. In the AC co-phase traction MG system, the rated phase is synchronized with the grid all the time. The proposed voltage and phase regulation are defined as:

$$
\begin{aligned}
& \dot{\theta}=\theta^{*}-m P+k_{\omega} \Delta \omega, \\
& \dot{E}=E^{*}-n Q+k_{e} \Delta e,
\end{aligned}
$$

where $m$ and $n$ represent the droop coefficients of the $\mathrm{P}-\mathrm{f}$ and $\mathrm{Q}-\mathrm{V}$ droops, respectively; $k_{\omega}$ and $k_{e}$ are the designed control gains; $\Delta \omega$ and $\Delta e$ are the designed secondary control variables:

$$
\begin{gathered}
\Delta \dot{\omega}=-k_{w}\left(\theta-\theta^{*}\right), \\
\Delta \dot{e}=-k_{e}\left(E-E^{*}\right) .
\end{gathered}
$$

By implementing integrators, the phase and voltage magnitude error is eliminated. Despite the effect of long-distance line impedance, the traction grid voltage is maintained in an acceptable range along the catenary line. Moreover, the circulation current is eliminated due to the elimination of the substation voltage difference.

\section{Stability Analysis}

\subsection{Modeling of System Operation States}

To derive the stability conditions for the proposed controller, a system small-signal model was developed. The following lemmas are introduced for the subsequent analysis.

Lemma 1 [28]: If $\mathrm{M}$ is positive definite and $\mathrm{N}$ is positive definite/semi-definite, then $\mathrm{M}+\mathrm{N}$ is positive definite/semi-definite.

To avoid unnecessary technical complications, we ignored the delay in adjusting the output frequency and modeled the delay in adjusting the output voltage magnitude as a first-order low-pass filter [29]. The system operation states under primary control can be modeled as:

$$
\begin{gathered}
\Delta \dot{\delta}_{i}=\omega_{i}-\omega^{*}=-m_{i} \frac{E_{i} E_{P}}{X_{i}} \sin \left(\Delta \delta_{i}\right)+\Delta \omega_{i}, \\
\omega_{v}{ }^{-1} \dot{E}=-\left(E_{i}-E^{*}\right)=-n_{i} \frac{\left(E_{i}-E_{P}\right) E_{P}}{X_{i}} \cos \left(\Delta \delta_{i}\right)+\Delta e_{i},
\end{gathered}
$$

where $E_{P}$ presents the equivalent voltage magnitude at point of common coupling (PCC); $X_{i}$ and $\Delta \delta_{i}=\delta_{i}-\delta_{P C C}$ represent the equivalent reactance and voltage phasor phase mismatch between the $i$ th DG and the PCC and $\omega_{v}$ represents the cut-off frequency of the equivalent low-pass filter from the output voltage adjustment; $\Delta \omega_{i}$ and $\Delta e_{i}$ are the designed secondary control variables. To derive the system's small-signal stability, it was assumed that $\sin \Delta \delta_{i}$ $\approx \Delta \delta_{i}$ and $E_{P} \approx E^{*}$. Additionally, referring to the conditions where the AC droop control is validated [30], it was assumed that in Equation (8), $E_{i} \approx E_{0}$ was constant, and in Equation (9), $\cos \Delta \delta_{i} \approx \cos \delta_{0}$ was constant. Then, the system operation states modeling can be reduced to:

$$
\begin{gathered}
\Delta \dot{\delta}_{i}=-m_{i} M_{i} \Delta \delta_{i}+\Delta \omega_{i}, \\
\omega_{v}{ }^{-1} \dot{E}_{i}=-E_{i}-n_{i} N_{i} E_{i}-\left(\frac{N_{i}}{\cos \delta^{\prime}}-1\right) E^{*}+\Delta e_{i},
\end{gathered}
$$

where $M_{i}=\frac{E^{\prime} \bullet E^{*}}{X_{\mathrm{i}}}$ and $N_{i}=\frac{\cos \delta^{\prime} \bullet E^{*}}{X_{i}}$. 
It is noteworthy that the time scale of the secondary control is at the millisecond level, while the variation of the system impedance, $X_{i}$ can be considered to be a constant at such a time scale. For subsequent analysis, $X_{i}$, and thus $M_{i}$ and $N_{i}$, are treated as constants. Denote $M=\operatorname{diag}\left(M_{i}\right), N=\operatorname{diag}\left(N_{i}\right), m=\operatorname{diag}\left(m_{i}\right)$, and $n=\operatorname{diag}\left(n_{i}\right)$. The proposed secondary controller is modeled as:

$$
\begin{aligned}
\Delta \dot{\omega}_{i} & =-k_{\omega}\left(\Delta \delta_{i}+\delta_{r e f}\right), \\
\Delta \dot{e}_{i} & =-k_{e}\left(E_{i}+E_{r e f}\right),
\end{aligned}
$$

where $k_{\omega}$ and $k_{e}$ are the designed control gains, while $\delta_{r e f}$ and $E_{r e f}$ represent the reference voltage and phase reference for each substation, respectively.

\subsection{Phase Regulation Stability}

Denote $m M=\operatorname{diag}\left(m_{i} M_{i}\right)$ and let $I$ represent the unit matrix and 0 represent the zero matrix. The linearized system model can be expressed in matrix form as:

$$
\stackrel{\bullet}{X}=W X+U
$$

where $X=(\Delta \delta / \Delta \omega)$ represents system states and $W=\left(\begin{array}{cc}-m M & I \\ -k_{\omega} I & 0\end{array}\right)=\left(\begin{array}{cc}-W_{1} & I \\ -W_{2} & 0\end{array}\right)$.

$U$ represents variables that are independent from $X$. The characteristic polynomial of $W$ can be simplified using a Schur complement and is derived as: $\operatorname{det}(s I-W)=\operatorname{det}(s I+$ $\left.W_{1}\right) \operatorname{det}\left(2 s I+s W_{1}+W_{2}\right)=0$. It can be concluded that $W_{1}$ is positive definite. The roots of $\operatorname{det}(s I-W)=0$ satisfies $\operatorname{Re}(s)<0$ if and only if the following conditions are satisfied:

$$
\begin{aligned}
& \lambda_{\min }\left(W_{1}+W_{1}^{T}\right)>0, \\
& \lambda_{\min }\left(W_{2}+W_{2}^{T}\right)>0 .
\end{aligned}
$$

Conditions (17) and (18) are satisfied as both $W_{1}$ and $W_{2}$ are positive definite. Therefore, it can be concluded that the system is exponentially stable with the proposed controller.

\subsection{Voltage Regulation Stability}

Denote $n N=\operatorname{diag}\left(n_{i} N_{i}\right)$. The linearized system model can be expressed in matrix form as:

$$
\dot{X}=\omega_{v} W X+\omega_{v} U,
$$

where $X=(\Delta E / \Delta e)$ represents the system states $W=\left(\begin{array}{cc}-1+n N & I \\ -k_{e} I & 0\end{array}\right)=\left(\begin{array}{cc}-W_{1} & I \\ -W_{2} & 0\end{array}\right)$.

$U$ represents variables that are independent from $X$. The characteristic polynomial of $W$ can be simplified using a Schur complement and is derived as: $\operatorname{det}(s I-W)=\operatorname{det}(s I$ $\left.+W_{1}\right) \operatorname{det}\left(2 s I+s W_{1}+W_{2}\right)=0$. It can be concluded that $W_{1}$ is positive definite, referring to Lemma 1. The roots of $\operatorname{det}(s I-W)=0$ satisfies $\operatorname{Re}(s)<0$ if and only if the following conditions are satisfied:

$$
\begin{aligned}
& \lambda_{\min }\left(W_{1}+W_{1}^{T}\right)>0, \\
& \lambda_{\min }\left(W_{2}+W_{2}^{T}\right)>0 .
\end{aligned}
$$

Conditions (20) and (21) are satisfied as both $W_{1}$ and $W_{2}$ are positive definite. Therefore, it can be concluded that the system is exponentially stable with the proposed controller.

\section{Results}

To verify the proposed decentralized control strategy for the AC co-phase traction MG power system, simulations using MATLAB/Simulink were studied. The single-phase AC traction voltage RMS value was rated as $400 \mathrm{~V}$, the unite line impedance of the catenary was defined as $0.076+\mathrm{j} 0.176 \Omega / \mathrm{km}$. The locomotive load was modeled as a $10 \Omega$ resistor parallel with a $50 \mathrm{mH}$ inductor. The structure of the traction power system under simulation 
is presented in Figure 4. Three substations and two locomotive loads were involved. L1, L2, L3, and L4 represent the line impedances between the load and the substation. Comparison results regarding the system's operational stability, circulation current elimination, and load voltage drop regulation are carried out in the following sections.

\subsection{Voltage/Frequency Regulation}

As previously discussed, compared to the conventional large-scale power grid, the operational stability of an AC co-phase traction grid can be easily affected by the line impedance and load condition and could be improved by the proposed control strategy. In this section, compared to the traditional control strategy in [4], the simulation results for the system stability under different conditions are discussed. In Figure 4, the proposed control strategy was adopted by all the substations SS1, SS2, and SS3. All the substations operated as a voltage source. With the same system structure, there was only one voltage source SS1 that supported the traction grid voltage in the former research, while SS2 and SS3 operated as power sources. The output voltage waveforms are given when the substation that is connected with the traction grid has a different load condition.

\subsubsection{No-Load Condition}

In this simulation, SS1 was connected to the traction grid at $0 \mathrm{~s}$, SS2 was connected to the traction grid at $3 \mathrm{~s}$, SS3 was connected to the traction grid at $6 \mathrm{~s}$, load 1 is connected to the traction grid at $9 \mathrm{~s}, \operatorname{load} 2$ is connected to the traction grid at $12 \mathrm{~s}$. The lengths of $\mathrm{L} 1=$ $\mathrm{L} 2=\mathrm{L} 3=\mathrm{L} 4=3$, which means the load was connected at the middle point between the two substations

As shown in Figure 5a, as the only voltage source, SS1 kept a constant output voltage V1 all the time. At time T1, SS2 was connected with the traction grid. The voltage reference for the voltage loop was only affected by line impedances L1 and L2. The output voltage of SS2 V2 went to a steady state after nearly $1 \mathrm{~s}$ of dynamic response. At T2, SS3 was connected with the traction grid. The voltage reference for the voltage loop was affected by line impedances L1, L2, L3, and L4. The output voltage of SS3 V3 went to a steady state after nearly $1 \mathrm{~s}$ of dynamic response. It can be seen that V3 was getting smaller than $\mathrm{V} 2$, because of the voltage droop on the bigger line impedance. Load 1 and load 2 were connected with the grid at T3 and T4, respectively. After a quick dynamic response, the entire system maintained a steady state.

The simulation results for the proposed control strategy are shown in Figure 5b. In this AC co-phase traction MG, all the substations were operating as voltage sources. There was a dynamic process when SS1 was connected with the traction. Due to the additional droop and secondary control, the speed of the system dynamic response was affected. However, same as SS2 and SS3, all the substations had a steady output voltage after $1 \mathrm{~s}$. The voltage reference for the voltage loop was no longer just the sampling value on the grid. It depended on the power consumption according to the control strategy. All the output voltages were steady after load 1 and load 2 were connected with the grid.

\subsubsection{On-Load Condition}

To validate the system stability under different load conditions, the substation was connected to the grid with a load. SS1 was connected to the traction grid at $0 \mathrm{~s}$, load 1 was connected to the traction grid at $3 \mathrm{~s}$, SS2 was connected to the traction grid at $6 \mathrm{~s}$, load 2 was connected to the traction grid at $9 \mathrm{~s}$, and SS3 was connected to the traction grid at $12 \mathrm{~s}$. All the loads were still connected at the middle point of two substations. The simulation results are shown in Figure 6. 


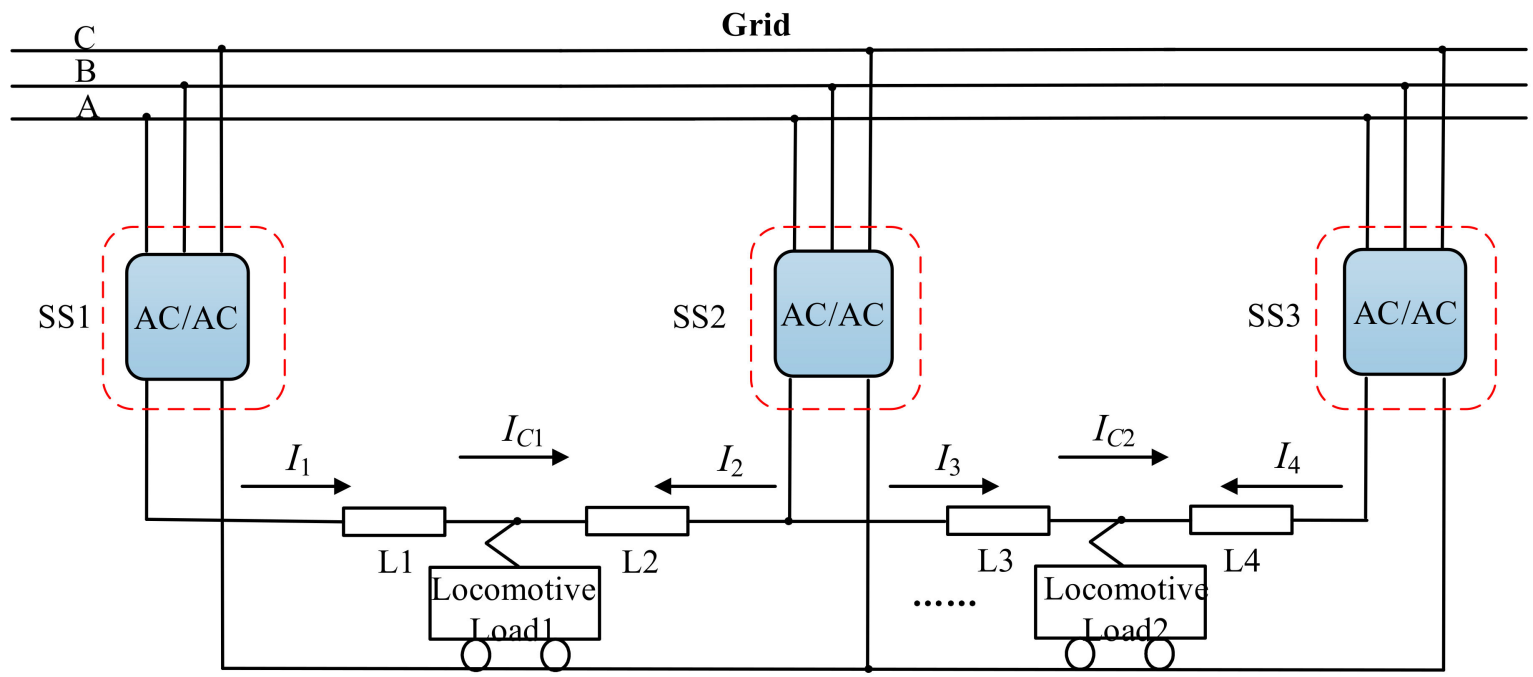

Traction Grid

Figure 4. The structure of the traction microgrid system for the simulation model.

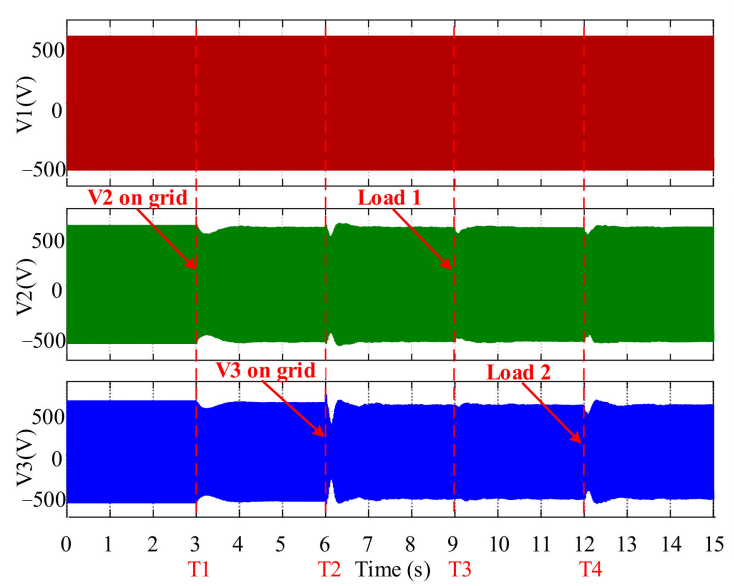

(a)

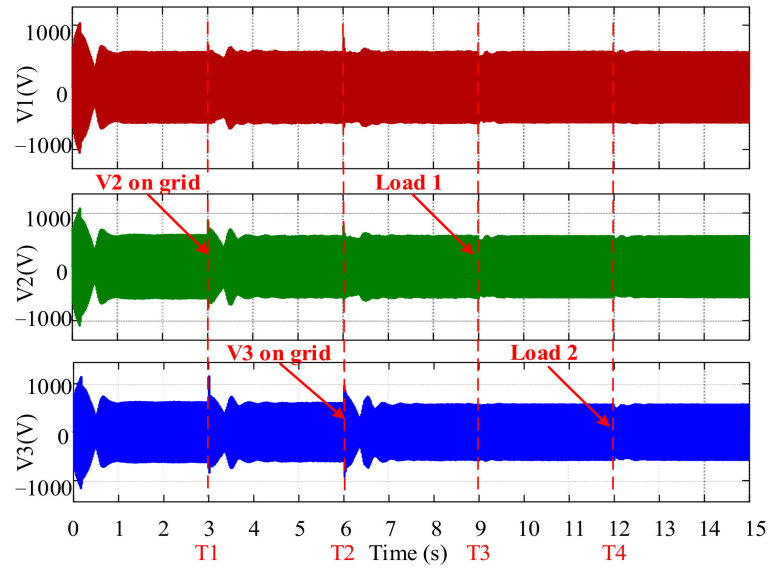

(b)

Figure 5. Three substation output voltages of different control strategies under a no-load condition: (a) the traditional control strategy; (b) the proposed strategy.

As shown in Figure 6a, SS1 kept a constant output voltage V1 all the time. The system was stable until SS3 was connected to the traction grid. Before T3, there were already two loads on the grid. The voltage reference error of SS3 had a great effect on the system's stability. In contrast, the system remained stable under on-load conditions. Based on the decentralized control strategy, the inverter of the substation not only provided the power consumption but also stabilized the traction grid voltage. In addition, when the line impendence was getting bigger, the stability of the proposed system was guaranteed, while the system became unstable in [4].

\subsection{Circulation Current}

A circulation current between substations is one of the key issues for a system's efficiency and lifetime. Same as the section before, two load conditions will be discussed. The voltage difference and circulation current comparison results are given in the following. 


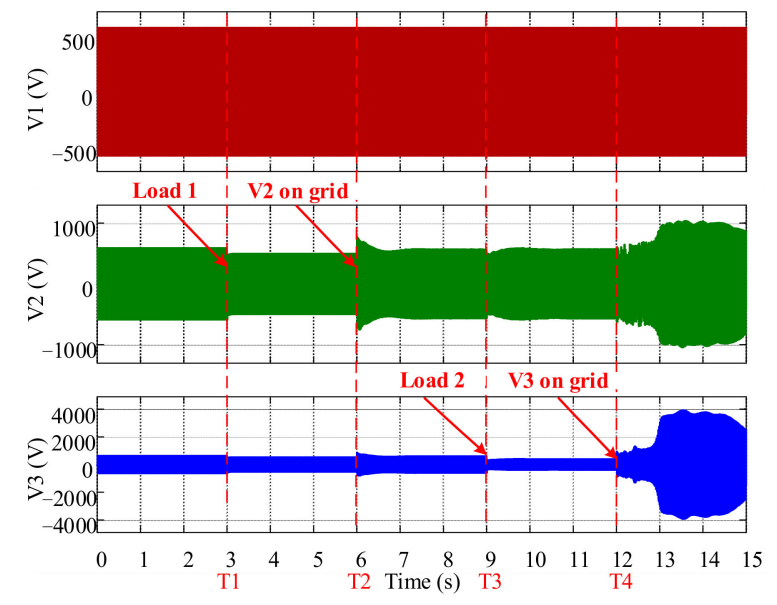

(a)

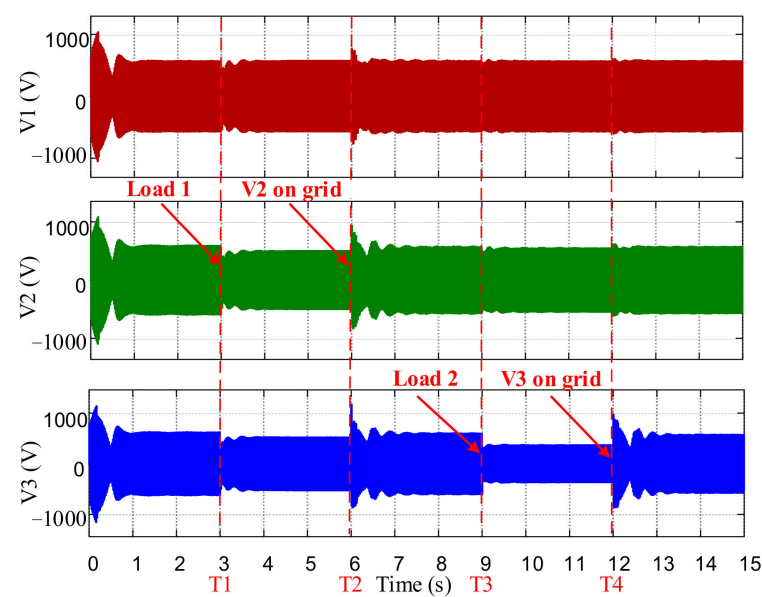

(b)

Figure 6. Three substation output voltages of different control strategies under on-load conditions: (a) the traditional control strategy; (b) the proposed strategy.

\subsubsection{No-Load Condition}

With the same no-load condition as before, the loads were connected to the grid after all the substations were on-grid. As it can be observed, Figure 7 gives the voltage difference $\mathrm{V} 1$ - V2 and V2 - V3 results of different control strategies under no-load conditions. In Figure 7a, when the loads connected to the grid, V1 - V2 and V2 - V3 had dynamic responses every time, which indicates that the system was sensitive to the load condition. In contrast, the voltage differences with the proposed strategy displayed better dynamic performance.

For the steady-state part, the zoomed-in results at the last second are given in Figure 8. It can be seen that nearly $50 \%$ of the voltage difference was cut down by the application of the proposed control strategy for the traction MG.

With the decrease of the voltage difference, the circulation current could be eliminated. The circulation currents' results with different strategies are depicted in Figure 9. $\mathrm{I}_{\mathrm{C} 1}$ is the circulation current between SS1 and SS2, while $\mathrm{I}_{\mathrm{C} 2}$ is the circulation current between SS2 and SS3. In this simulation, the line impedances of L1, L2, L3, and L4 were same. According to $(3), \mathrm{I}_{\mathrm{C} 1}=0.5(\mathrm{I} 1-\mathrm{I} 2)$, while $\mathrm{I}_{\mathrm{C} 2}=0.5(\mathrm{I} 3-\mathrm{I} 4)$. It can be seen that the circulation current was relative to the voltage difference in Figure 9.

In the zoomed-in results in the steady state for the last second, $\mathrm{I}_{\mathrm{C} 1}=15 \mathrm{~A}$ and $\mathrm{I}_{\mathrm{C} 2}=8$ A with the traditional strategy, while $\mathrm{I}_{\mathrm{C} 1}=5 \mathrm{~A}$ and $\mathrm{I}_{\mathrm{C} 2}=1 \mathrm{~A}$ with the proposed strategy. The circulation current was reduced by more than $66 \%$.

\subsubsection{On-Load Condition}

As seen in Figure 6, the system was unstable after SS3 connected to the grid with the traditional strategy. As a result, the voltage differences increased, which caused a large circulation current, as shown in Figure 10a. However, the voltage differences remained in an acceptable range with the proposed control strategy in Figure 10b. 


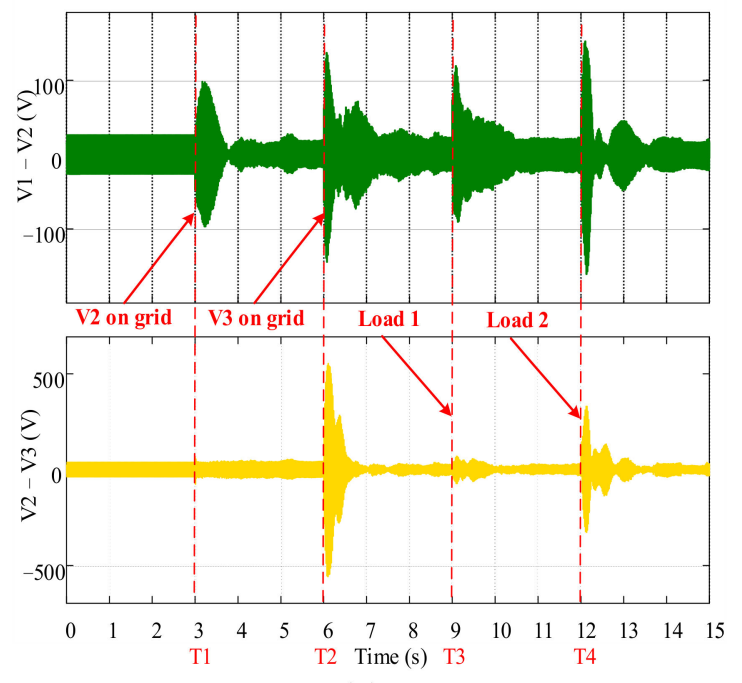

(a)

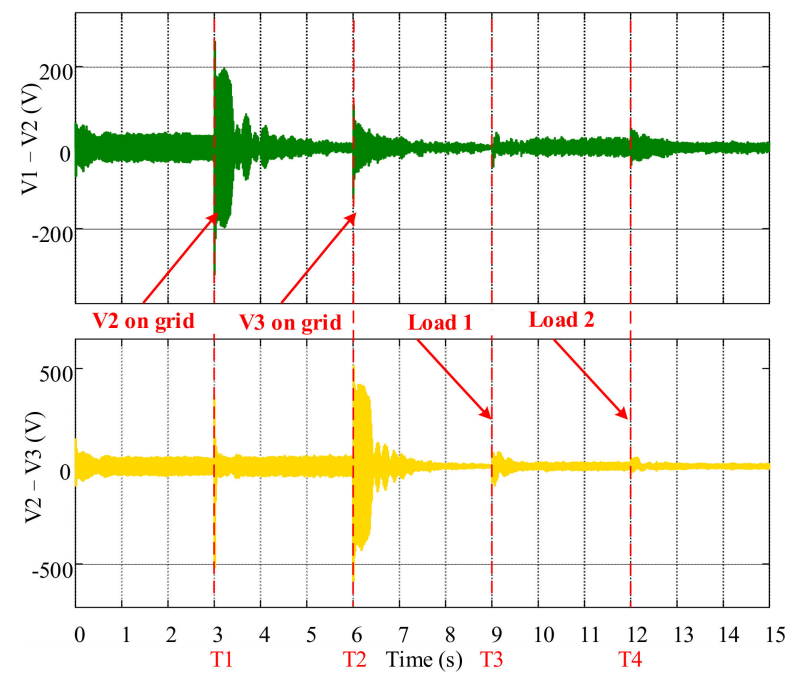

(b)

Figure 7. The voltage differences different control strategies under no-load conditions: (a) the traditional control strategy; (b) the proposed strategy.
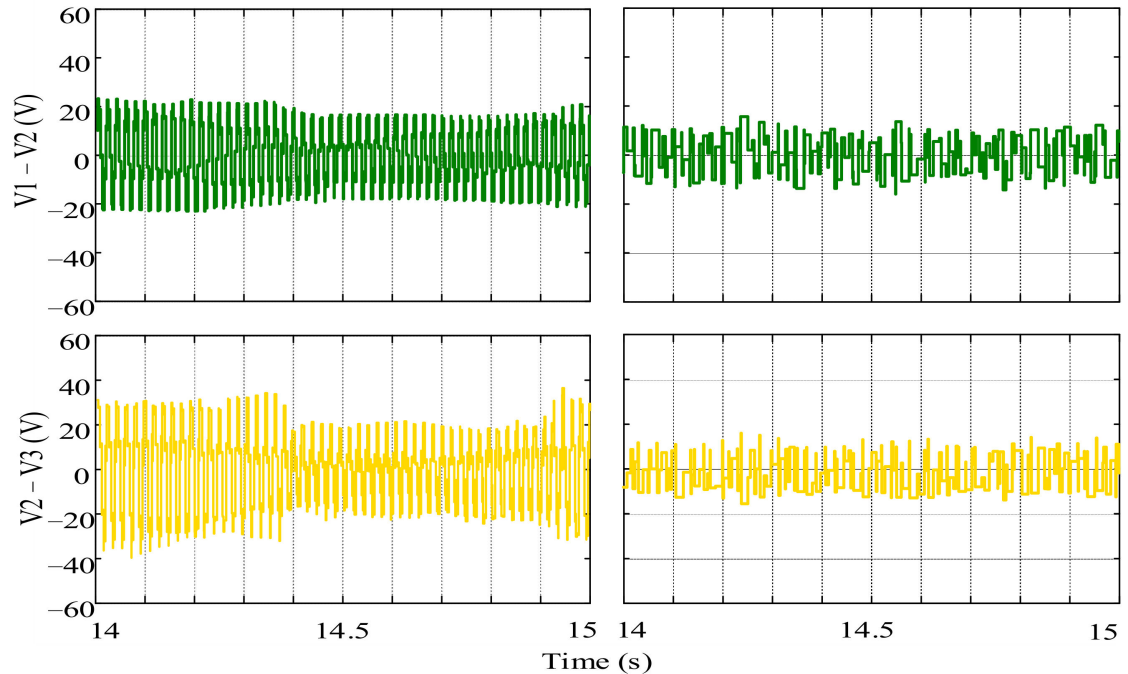

(a)

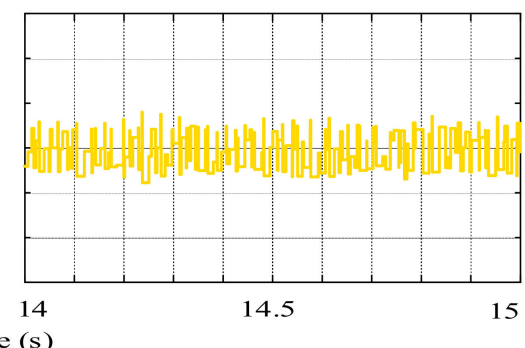

(b)

Figure 8. The zoomed-in voltage differences in the steady state under a no-load condition: (a) the traditional control strategy; (b) the proposed strategy.

The zoomed-in results of the voltage differences and circulation currents of the proposed strategy at the last second are also given in Figure 11. Both V1 - V2 and V2 - V3 were less than $20 \mathrm{~V}$. $\mathrm{I}_{\mathrm{C} 1}$ and $\mathrm{I}_{\mathrm{C} 1}$ were smaller than $5 \mathrm{~A}$. The circulation currents between substations were eliminated under the on-load conditions. 

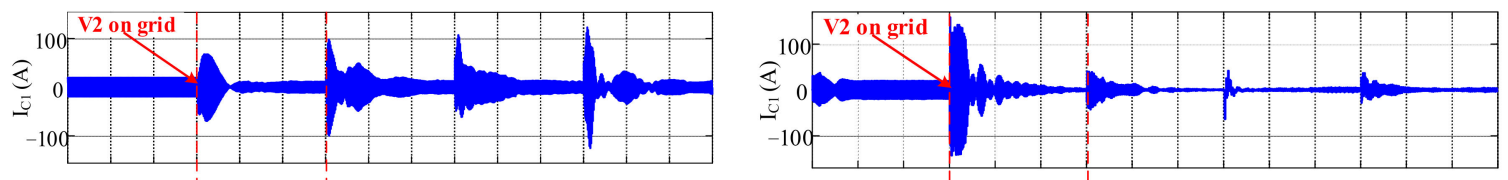

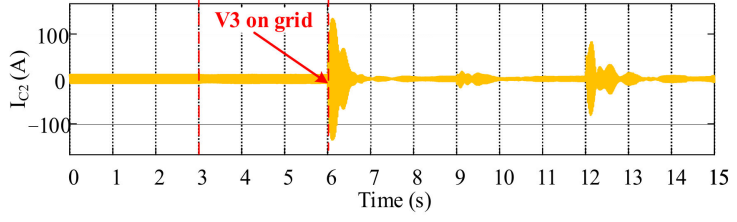

(a)

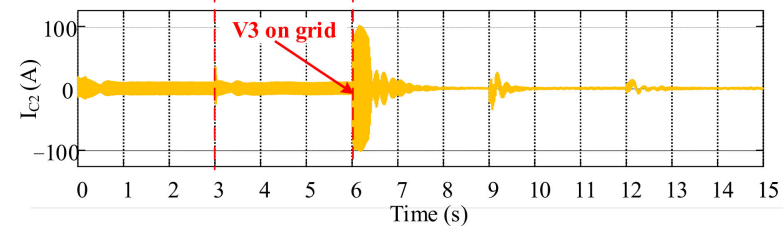

(b)

Figure 9. The circulation currents when they were connected with the traction grid without a load: (a) the traditional control strategy; (b) the proposed strategy.
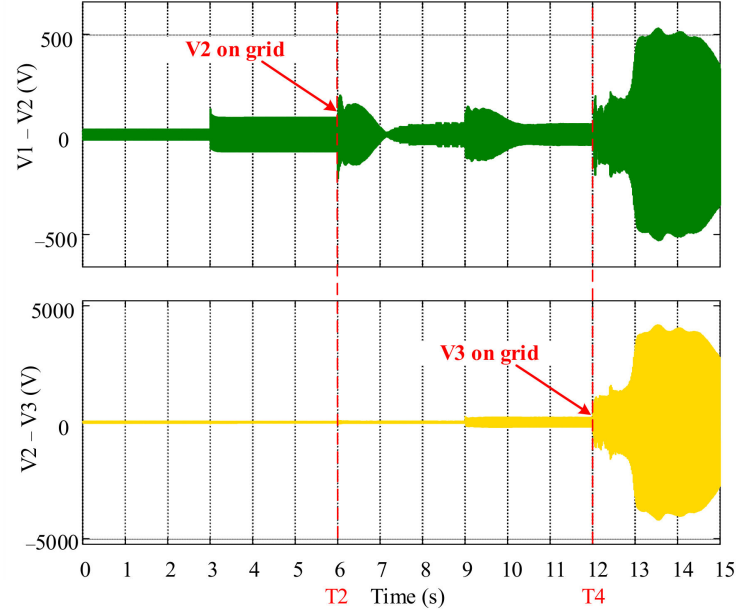

(a)
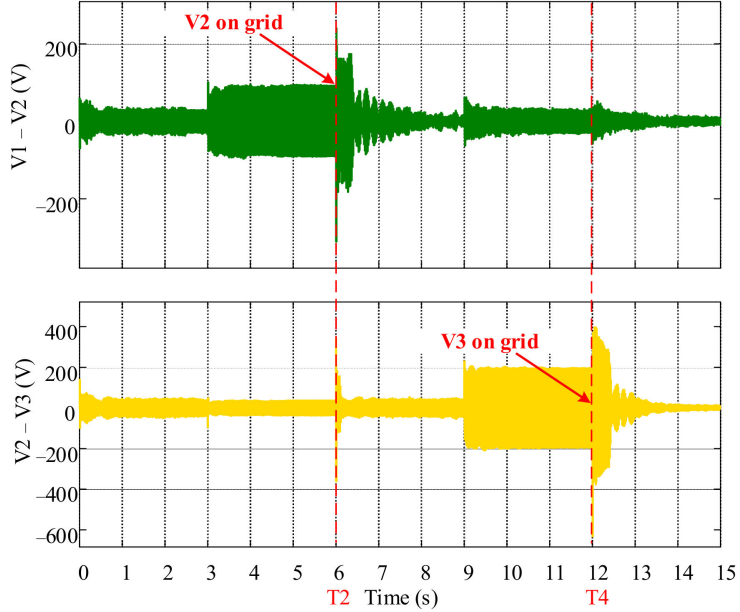

(b)

Figure 10. The voltage differences when they were connected with the traction grid with a load: (a) the traditional control strategy; (b) the proposed strategy.

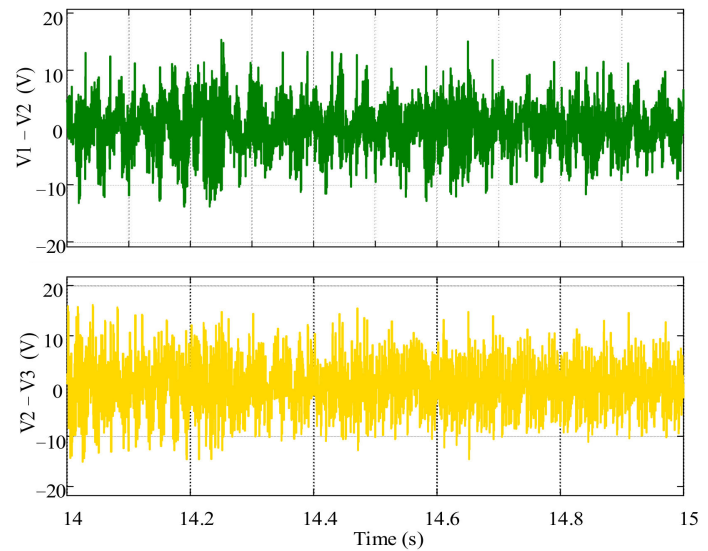

(a)
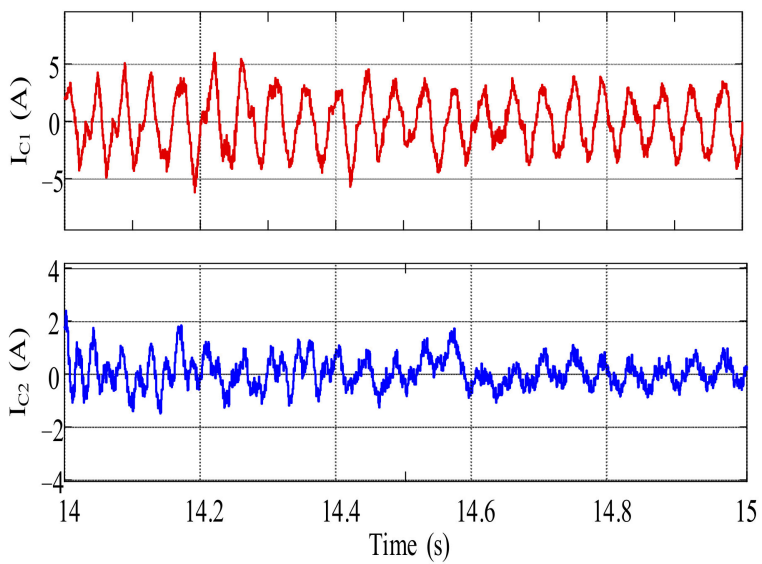

(b)

Figure 11. The zoomed-in voltage differences (a) and circulation currents; (b) in the steady state when they were connected with the traction grid without a load with the proposed strategy. 


\subsection{Power Sharing/Voltage Drop}

In the existing traction grid, only one substation provides the power for one interval due to the neutral section.

There was an obvious voltage drop at the end of the catenary. The situation was different with the proposed traction MG system. The simulation was modified based on the structure in Figure 4. As shown in Figure 12, six same-value line impedances L were connected in series. SS1, SS2, SS3, and load 1 were already connected to the grid before $8 \mathrm{~s}$. Load 2 was connected to the traction grid at $8 \mathrm{~s}, 10 \mathrm{~s}, 12 \mathrm{~s}, 14 \mathrm{~s}$, and $16 \mathrm{~s}$ in sequence. The length of $\mathrm{L}$ was $1 \mathrm{~km}$, which is a reasonable number considering the speed of the locomotive and the system response. For the traditional traction grid simulation, only SS2 supported the load consumption.

The current and the voltage of the load comparison results with different traction grids is given in Figure 13. As shown in Figure 13a, the output current of SS2, namely ISS2, was getting smaller when load 2 moved away from the station. With the line impedance increase, the load voltage was getting smaller too. As a result, it was hard to meet the voltage requirement when the load was far away from the station. Compared to the traditional traction grid, there was only a small voltage drop on the load in the proposed AC co-phase traction grid. As can be seen in Figure 13a, there were two output currents from SS2 and SS3, which were ISS2 and ISS3, respectively. When the load moved from SS2 to SS3, ISS2 became smaller, while ISS2 got bigger. The largest voltage drop happened when the load was moving at the middle point. As seen in the analysis in Section 3, the load got more power from the near substation. The line-impedance-based power-sharing required no additional control and could maintain the load voltage in an acceptable range all the time. 


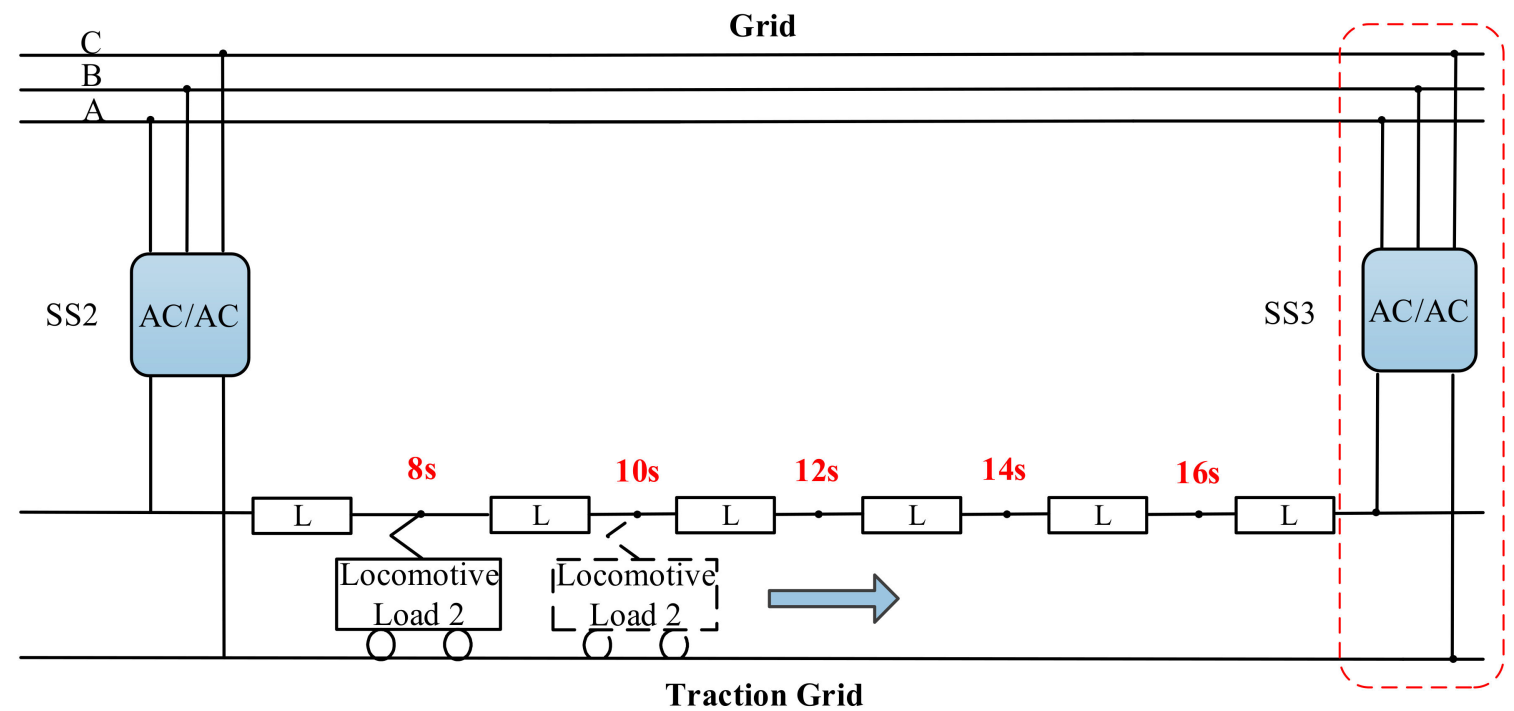

Figure 12. The system structure when the load is moving.
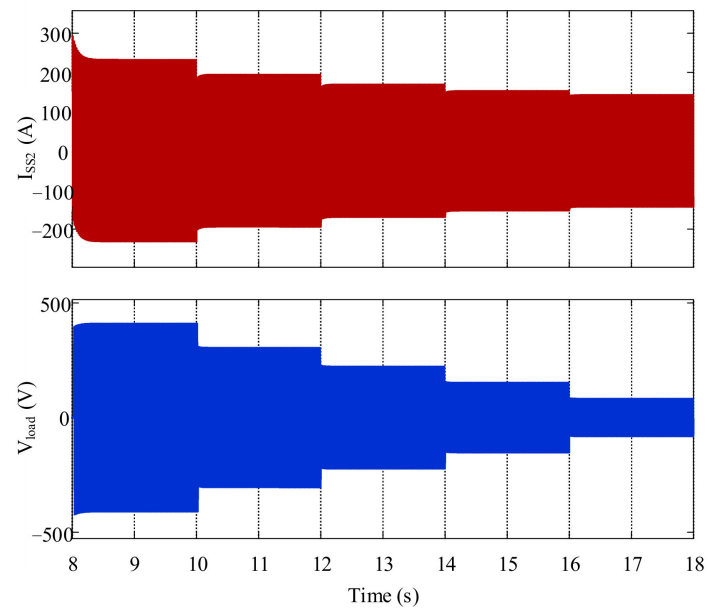

(a)
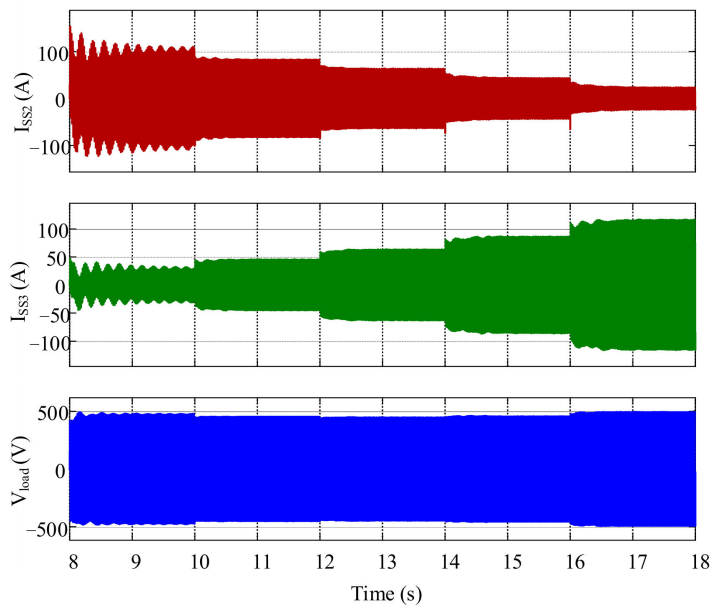

(b)

Figure 13. Output current and load voltage of different traction grids: (a) the traditional traction grid (b) the proposed AC co-phase traction grid.

\section{Conclusions}

In this study, the AC co-phase traction MG system structure was introduced. To improve the system's operating performance, a decentralized control strategy was designed for the converter-based substation. A small-signal stability analysis was presented for the proposed controller. Finally, the proposed work was validated through extensive simulations. With the proposed decentralized control strategy, the system's stability was improved under various load and line impedance conditions. The circulation current was reduced by more than $66 \%$, which indicates the higher efficiency of the system. In addition, the quality of the load voltage was guaranteed despite the significant effect of the line impedance. With the simplified control and power-sharing strategy, additional substations can be easily integrated for further increases of the system's capacity for future high-speed trains. Moreover, without communications between the substations or to the grid, "plug-and-play" functionality is realized. In the following research, optimization of the control parameters for the system's robustness and the application of distributed renewable energy in the traction MG will be further studied. 
Author Contributions: Conceptualization, L.M. and Z.S.; methodology, Y.D.; software, L.M.; validation, Y.D., L.M. and L.Z.; formal analysis, Y.D.; investigation, F.Y.; resources, S.X.; data curation, L.Z.; writing-original draft preparation, L.M.; writing—review and editing, Y.D.; visualization, Z.S.; supervision, Z.S.; project administration, School of Electrical Engineering Southwest Jiaotong University; funding acquisition, Southwest Jiaotong University. All authors have read and agreed to the published version of the manuscript.

Funding: This research was funded by [Basic scientific research operating expenses of central universities] grant number [2682020CX24].

Conflicts of Interest: The authors declare no conflict of interest.

\section{References}

1. Xie, B.; Li, Y.; Zhang, Z.; Hu, S.; Zhang, Z.; Luo, L.; Cao, Y.; Zhou, F.; Luo, R.; Long, L. A Compensation System for Cophase High-Speed Electric Railways by Reactive Power Generation of SHC\&SAC. IEEE Trans. Ind. Electron. 2018, 65, 2956-2966.

2. Shu, Z.; Xie, S.; Lu, K.; Zhao, Y.; Nan, X.; Qiu, D.; Zhou, F.; Gao, S.; Li, Q. Digital Detection, Control, and Distribution System for Co-Phase Traction Power Supply Application. IEEE Trans. Ind. Electron. 2012, 60, 1831-1839. [CrossRef]

3. Li, Q.; Liu, W.; Shu, Z.; Xie, S.; Zhou, F. Co-phase power supply system for HSR. In Proceedings of the 2014 International Power Electronics Conference (IPEC-Hiroshima 2014-ECCE ASIA), Hiroshima, Japan, 18-21 May 2014; pp. 1050-1053.

4. He, X.; Shu, Z.; Peng, X.; Zhou, Q.; Zhou, Y.; Zhou, Q.; Gao, S. Advanced Cophase Traction Power Supply System Based on Three-Phase to Single-Phase Converter. IEEE Trans. Power Electron. 2014, 29, 5323-5333. [CrossRef]

5. Shu, Z.; He, X.; Wang, Z.; Qiu, D.; Jing, Y. Voltage Balancing Approaches for Diode-Clamped Multilevel Converters Using Auxiliary Capacitor-Based Circuits. IEEE Trans. Power Electron. 2013, 28, 2111-2124. [CrossRef]

6. Mahmood, H.; Michaelson, D.; Jiang, J. Reactive Power Sharing in Islanded Microgrids Using Adaptive Voltage Droop Control. IEEE Trans. Smart Grid 2015, 6, 3052-3060. [CrossRef]

7. Mao, M.Q.; Dong, Z.; Ding, Y.; Chang, L. A unified controller for a microgrid based on adaptive virtual impedance and conductance. In Proceedings of the 2014 IEEE Energy Conversion Congress and Exposition (ECCE), Pittsburgh, PA, USA, 15-18 September 2014; pp. 695-701.

8. Zhong, Q.-C. Robust Droop Controller for Accurate Proportional Load Sharing Among Inverters Operated in Parallel. IEEE Trans. Ind. Electron. 2013, 60, 1281-1290. [CrossRef]

9. Du, Y.; Lu, X.; Wang, J.; Lukic, S. Distributed Secondary Control Strategy for Microgrid Operation with Dynamic Boundaries. IEEE Trans. Smart Grid 2019, 10, 5269-5282. [CrossRef]

10. Lee, T.-Z.; Cheng, P.-T. Design of a New Cooperative Harmonic Filtering Strategy for Distributed Generation Interface Converters in an Islanding Network. IEEE Trans. Power Electron. 2007, 22, 1919-1927. [CrossRef]

11. He, J.; Li, Y.; Guerrero, J.M.; Blaabjerg, F.; Vasquez, J.C. An Islanding Microgrid Power Sharing Approach Using Enhanced Virtual Impedance Control Scheme. IEEE Trans. Power Electron. 2013, 28, 5272-5282. [CrossRef]

12. Blaabjerg, F.; Chen, Z.; Kjaer, S. Power Electronics as Efficient Interface in Dispersed Power Generation Systems. IEEE Trans. Power Electron. 2004, 19, 1184-1194. [CrossRef]

13. Rocabert, J.; Luna, A.; Blaabjerg, F.; Rodríguez, P. Control of Power Converters in AC Microgrids. IEEE Trans. Power Electron. 2012, 27, 4734-4749. [CrossRef]

14. He, J.; Li, Y.W. Analysis, Design, and Implementation of Virtual Impedance for Power Electronics Interfaced Distributed Generation. IEEE Trans. Ind. Appl. 2011, 47, 2525-2538. [CrossRef]

15. Brabandere, K.D.; Bolsens, B.; Keybus, J.V.D.; Woyte, A.; Driesen, J.; Belmans, R.; Leuven, K. A voltage and frequency droop control method for parallel inverters. IEEE Trans. Power Electron. 2007, 22, 1107-1115. [CrossRef]

16. Yao, W.; Chen, M.; Matas, J.; Guerrero, J.M.; Qian, Z. Design and Analysis of the Droop Control Method for Parallel Inverters Considering the Impact of the Complex Impedance on the Power Sharing. IEEE Trans. Ind. Electron. 2011, 58, 576-588. [CrossRef]

17. Han, Y.; Li, H.; Shen, P.; Coelho, E.A.A.; Guerrero, J.M. Review of Active and Reactive Power Sharing Strategies in Hierarchical Controlled Microgrids. IEEE Trans. Power Electron. 2016, 32, 2427-2451. [CrossRef]

18. Li, Y.W.; Kao, C.-N. An Accurate Power Control Strategy for Power-Electronics-Interfaced Distributed Generation Units Operating in a Low-Voltage Multibus Microgrid. IEEE Trans. Power Electron. 2009, 24, 2977-2988. [CrossRef]

19. Chen, Y.; Luo, A.; Zhou, J.; Bai, L.; Tu, C. Rapid reactive power control method for parallel inverters using resistive-capacitive output impedance. In Proceedings of the 2013 1st International Future Energy Electronics Conference (IFEEC), Tainan, Taiwan, 3-6 November 2013; pp. 98-102.

20. Gu, Y.; Li, W.; He, X. Frequency-Coordinating Virtual Impedance for Autonomous Power Management of DC Microgrid. IEEE Trans. Power Electron. 2015, 30, 2328-2337. [CrossRef]

21. Sreekumar, P.; Khadkikar, V. A new virtual harmonic impedance scheme for harmonic power sharing in an islanded microgrid. IEEE Trans. Power Del. 2016, 31, 936-945. [CrossRef]

22. Milczarek, A.; Malinowski, M.; Guerrero, J.M. Reactive Power Management in Islanded Microgrid-Proportional Power Sharing in Hierarchical Droop Control. IEEE Trans. Smart Grid 2015, 6, 1631-1638. [CrossRef] 
23. Du, Y.; Tu, H.; Lukic, S. Distributed Control Strategy to Achieve Synchronized Operation of an Islanded MG. IEEE Trans. Smart Grid 2018, 10, 4487-4496. [CrossRef]

24. Liu, S.; Wang, X.; Liu, P.X. Impact of Communication Delays on Secondary Frequency Control in an Islanded Microgrid. IEEE Trans. Ind. Electron. 2015, 62, 2021-2031. [CrossRef]

25. Li, Q.; Chen, F.; Chen, M.; Guerrero, J.M.; Abbott, D. Agent-Based Decentralized Control Method for Islanded Microgrids. IEEE Trans. Smart Grid 2016, 7, 637-649. [CrossRef]

26. Liu, X.; Wang, P.; Loh, P.C. A Hybrid AC/DC Microgrid and Its Coordination Control. IEEE Trans. Smart Grid 2011, 2, 278-286. [CrossRef]

27. Ahumada, C.; Cardenas, R.; Saez, D.; Guerrero, J.M. Secondary Control Strategies for Frequency Restoration in Islanded Microgrids With Consideration of Communication Delays. IEEE Trans. Smart Grid 2016, 7, 1430-1441. [CrossRef]

28. Roger, A.H.; Charles, R.J. Matrix Analysis; Cambridge University Press: Cambridge, UK, 1990.

29. Simpson-Porco, J.W.; Shafiee, Q.; Dörfler, F.; Vasquez, J.C.; Guerrero, J.M.; Bullo, F. Secondary frequency and voltage control of islanded microgrids via distributed averaging. IEEE Trans. Ind. Electron. 2015, 62, 7025-7038. [CrossRef]

30. Guerrero, J.M.; Vasquez, J.C.; Matas, J.; De Vicuña, L.G.; Castilla, M. Hierarchical control of droop-controlled ac and dc microgrids-A general approach toward standardization. IEEE Trans. Ind. Electron. 2011, 58, 158-172. [CrossRef] 